\title{
Baseline Hematocrit Values in Birds: an Important Tool for Monitoring Exposure to Polycyclic Aromatic Hydrocarbons
}

\author{
Sheila A Scoville, J Peter Doherty \\ Department of Pathologv and Anatomv. Eastern Virginia Medical School \\ Email: scovilsa@evms.edu
}

\begin{abstract}
Avian hematocrit can be used to monitor the effects of polycyclic aromatic hydrocarbons during the aftermath of oil spills and their cleanup. Exposure to PAHs can result in a rapid and dramatic drop in hematocrit. Some baseline hematocrit data has been reported for waterbirds before and during coastline spills, but the equivalent baseline hematocrit data does not exist for monitoring land-based spills affecting migratory and resident songbirds. In this study, blood samples were taken from 310 North American migratory birds on their wintering grounds in The Bahamas and Panama. Hematocrit was measured in 20 species of passerines and near passerines plus one shorebird species. The results show that hematocrit values rose prior to northbound migration in mid-March to midApril when samples were compared to those taken in January. Among those species able to be reliably sexed by plumage, increases in hematocrit were found only in males. Hematocrit samples from 8 neo-tropical species and one avian family met new guidelines for determining reference intervals as published by The American Society of Veterinary Clinical Pathologists. This study establishes hematocrit baseline values for a portion of the annual cycle of these neo-tropical migrant species and explains how monitoring changes in hematocrit after polycyclic aromatic hydrocarbon exposure can be used to determine injury and possible recovery after an oil spill.
\end{abstract}

Keywords. Hemolytic anemia, polycyclic aromatic hydrocarbons, avian hematocrit, reference intervals, neotropical birds, Arenaria, Paridae

\section{Introduction}

\subsection{Background}

Among serious threats to the health of avian populations is hemolytic anemia from oil spills (Leighton et al., 1983). Exposure to oil is by preening and ingestion of contaminated prey items and by inhalation of related toxic substances. Spills occur both on land and along waterways from rail cars, pipeline ruptures and unintentional releases from storage facilities. Migratory birds are vulnerable to this and other threats in any portion of their annual cycle. On land, the United States Department of Transportation Pipelines and Materials Safety Administration reports that more than 110 million gallons of oil and petroleum products have spilled from over 5600 pipeline ruptures in 47 states since 1990, with spills in Texas, Oklahoma and Louisiana accounting for around half of that volume (PHMSA Pipeline Safety, Data \& Reports). In May 2017, 94,000 gallons of jet fuel were spilled from a Navy storage facility in Virginia Beach, Virginia (usnews.com May 12, 2017). In the Virginia Beach incident, a small number of birds were collected as dead specimens, yet injury to avians from this and other spills is largely undetermined.

Effects on waterbirds from coastal spills are somewhat better understood. Leighton et al. (1983) determined that the primary effect on birds from ingesting oil was hemolytic anemia. Herring gulls and puffins experimentally dosed with crude oil showed a dramatic drop in hematocrit, at some dosages, after four days. A subsequent investigation established injury to multiple organs (Leighton, 1986). Studies conducted in conjunction with the Deepwater Horizon oil spill corroborated these findings concluding that damage to red blood cells by metabolites of polycyclic aromatic hydrocarbons (PAHs) common to all petroleum products and oil spills, resulted in reduction of the oxygen carrying capacity of the blood (Gulf Spill Restoration, 2015). As exposure to PAHs is not always apparent, comparison to known hematocrit reference intervals (RIs) by species, genera or family could be used to objectively 
determine exposure to PAHs following coastal or land-based oil spills. The prospective collection of baseline blood values for migratory birds across their annual cycle is essential to evaluate anemia due to PAHs exposure from petrochemicals.

While sophisticated assays can be made in the laboratory measuring parameters of blood proteins or stress hormones, in the circumstance of evaluating PAH toxin-exposed birds in the field, arguably the single most useful indicator for the evaluation of health is hematocrit (HCT), often referred to interchangeably as packed cell volume (PCV). Samples can be collected with a minimally invasive procedure and analyzed in the field with few supplies and transportable equipment. Field conditions including temperature and sample storage time can compromise the reliability of other laboratory tests. Additionally, point-of-care instruments used by some investigators to measure HCT remotely are expensive and require repeated calibration to insure reliability.

This study measured the hematocrit of 310 migrants on their wintering grounds in The Bahamas and Panama. Reference intervals, partitions and histograms are reported as per the guidelines of the American Society of Veterinary Clinical Pathologists (ASVCP). Normal hematocrit values for migratory North American birds are known for very few species throughout their annual cycle. The current data are widely fragmented. The sample size of a species is often small and evaluated without regard to the segment of the annual cycle during which it was obtained. Much of the literature concerning avian hematocrit was reviewed in Fair et al, (2007). Most of these reports are for waterfowl and raptors. Only a very few reports are for neo-tropical passerines. A very limited number of these species reports have a sufficient sample size with which to determine the normal distribution of any reported blood value. In a recent review, authors identified 27 North American species on which there is hematocrit data in at least a portion of their annual cycle (Glomski and Pica, 2011). Of these, fifteen have 1-9 subjects per group such as age or gender, eight have 11-19 and only four have more than 20 subjects. Low subject numbers are also typical in studies of Old World and Australian species, but among all summarized accounts, normal avian blood ranges from 30\% to mid-50\% hematocrit. About $15 \%$ of these species range from 35$40 \% \mathrm{HCT}$, about $5-10 \%$ of species were over $50 \%$, and the remainder was between 40 and $50 \%$ HCT. It is unknown how many of these values were determined with small sample sizes or whether those species have cyclical variations. It is also unknown whether samples were taken from only a portion of their annual cycle.

A recent article (Cray, 2015) iterates new guidelines issued by ASVCP establishing reference intervals (RIs) for avian species. These guidelines establish realistic numbers of subjects on which to base judgment of parameters of clinical animal health and are recommended for use in evaluating the health of wildlife. In addition to the gold standard of 120+ subjects, sample sizes of 20-40 are now deemed realistic for establishing normal parameters, including partitions (subdivisions) of the original RI. Age, sex, location, season, altitude and species are all important in generating partitions. While RIs should not be reported for subject numbers fewer than 20, sample sizes from 10-20 are considered useful when histograms accompany the summarized data. Most importantly, Cray asserts that these baseline values should be generated prospectively. This study measured the hematocrit of 310 migrants on their wintering grounds in The Bahamas and Panama. Reference intervals, partitions and histograms are reported as per the guidelines of the American Society of Veterinary Clinical Pathologists and provide the prospectively generated baseline hematocrit necessary to evaluate injury and possible recovery to exposure to PAHs from petroleum spills.

\section{Methods}

Blood samples were taken at multiple locations in The Bahamas in January, and again in mid-March through mid-April prior to northward migration in 2014 and 2015. One species, Protonotaria citrea (prothonotary warbler) was sampled in Panama in January, 2011. Passerines and one near passerine were captured in mist nets at all locations; one shorebird species, Arenaria interpres (ruddy turnstone) was captured using mist and whoosh nets, at several locations in The Bahamas. Standard field measurements and evaluations were taken including age, sex when possible by plumage, wing chord, tail length, tarsal length, weight, fat and muscle evaluation, reproductive status, molt and general health assessment. Each blood sample was taken by venipuncture to the brachial vein and collected into microcapillary tubes treated with ammonium heparin as EDTA has been shown to cause hemolysis in some 
neo-tropical migrants (Booth \& Elliot, 2003). Tubes were stored in an insulated carrier, processed and hematocrit read within 6 hours. Micro-hematocrit tubes were centrifuged at 12,000g for a minimum of 5 minutes (Campbell, 1984). Samples were collected from passerines during morning daylight hours. Blood samples were taken from A. interpres, (ruddy turnstones) throughout daylight hours. Birds sampled in The Bahamas were marked with a transverse cut made at a $45^{\circ}$ angle at the tip of the right outer rectrice to prevent repeated sampling. Redundant samples were included when possible to insure reliability. All samples were taken at elevations near sea level. Permits including approval of ethical standards employed in the study were issued by the Bahamas Environment Science and Technology Commission (BEST). Access to public lands for sample collection was also permitted by BEST, as well as The Bahamas National Trust. In Panama, permits were obtained from Autoridad Nacional del Ambiente de Panamá, now MIAMBIENTE, through la Sociedad Audubon de Panama. No species listed as endangered or threatened in The Bahamas or the United States were sampled.

\section{$3 \quad$ Statistics}

We used Sigmaplot 13.0 (Systat Software Inc.) to analyze data, and generate histograms. Normality was established with the Shapiro-Wilk test, and equal variance was determined with the Brown-Forsythe test. Reference intervals were calculated using EasyCalculation.com's Reference Range Calculation using Normal Distribution program. RIs, partitions and histograms are reported as per the guidelines of ASCVP as well as those additional histograms recommended for species with smaller samples (n 10-19).

\section{Results}

The mean hematocrit for the 8 neo-tropical species (n greater than 20) sampled on their wintering grounds ranged from 43.32 to 47.5 . The RIs at the $90 \%$ confidence interval for the upper and lower limits of normal HCT, accompanied by histograms for these species according to the ASCVP guidelines (Cray, 2015) are reported in Table 1 and Figure 1. The mean for all members of the family Paridae, twelve sampled species, was 46.13. The RI for that family (95\% CI) with partition RIs for samples taken in January and April, and for males and females are presented in Table 2 with histograms presented in Figure 2.

The mean hematocrit for warblers in The Bahamas increased significantly between January and midMarch/April, $(\mathrm{t}=2.559, \mathrm{P}=.011)$. The mean HCT for A. interpres, increased significantly between January and April, as well $(\mathrm{t}=3.78, \mathrm{P}=<.001)$. The increase for Dunetella carolinensis (gray catbirds) from 42.5 to 44.64 during these times was not significant but had a low power of the test, .376 compared to a desired .8, meaning that negative results may not accurately reflect possible differences. P. citrea in Panama were measured only in January. Among the sexually dimorphic species, those able to be reliably sexed at that time, females showed no increase in HCT (a small insignificant decrease, 46.5 to 45.6) between January and March/April while males showed a significant increase in HCT values when compared for the two sampling periods, 45.67 in January, 47.4 in March/April $(\mathrm{t}=2.013, \mathrm{P}=.047)$, also Figure 2. Many of the other species sampled were monomorphic or unreliably sexed during this portion of their annual cycle. No differences were found due to age when the HCT of second year birds was compared to that of after-second vear (SY vs. ASY). Groups shown in Table 2 are partitioned by sex and time of year: wintering (January-April), January alone and pre-migration (March-April).

Additional hematocrit values not meeting RI standards are reported. Three additional warbler species meet the veterinary guidelines for sample sizes of 10-19 in which histograms give an indication of the distribution of HCT value (Figure3). Other warbler species are included in the Paridae RI. The mean for two species from the genus Paserina (painted and indigo buntings) was 50 while the mean for three species of the genus Vireo) was 50, as well. Table 3 summarizes values from all species lacking RI sample numbers.

\section{$5 \quad$ Discussion and Conclusions}

Threats to migratory species are present at each segment of the annual cycle (Runge et al., 2015). Among these threats is exposure to toxic contaminants including petroleum products. Those assessing 
the Deepwater Horizon oil spill of 2010 were aware of the value of monitoring hematocrit in exposed birds (Gulf Spill Restoration, 2015) yet, the lack of baseline HCT values for most species hampered their ability to assess injury or recovery in birds known to have been exposed, or suspected of exposure, to petroleum products. A study determining the effect of parasite loads on blood values in neotropical birds in Belize (Booth \& Elliot, 2003) showed that, although parasite infected birds represented a range of hematocrit values in Belize, only neotropical migrants at the high end of the HCT range arrived at sampling sites in Louisiana. Non-parasite infected birds arrived with HCT levels equal to those in Belize suggesting that the additional stress of parasitism reduced survivability during migration. If parasitecompromised birds perish during migration with a decrease in hematocrit of 10-20\% below surviving birds, a reduced hematocrit induced by exposure to oil, possibly reduced by half (Leighton, 1983) could lead to disastrous results for migrating birds. In the real world, multiple affecters are likely to have a cumulative adverse effect.

The current report documents the HCT of one portion of the annual cycle of several neo-tropical avian species. While on their southern wintering grounds, HCT increased between the first sampling period (January) and the pre-migratory second period (mid-March to mid-April) for both individual species and for the family Paridae. When sex was determined in the field, only males showed the increase, but since many of the birds could not be reliably sexed by plumage, it is unclear whether all of the HCT increase is due to sex differences. A full understanding of the hematocrit of passerines during their annual cycle by gender would be helpful for monitoring purposes.

Importantly to this topic, hemolytic anemia is a regenerative anemia. If birds survive their weakened state, a return to normal hematocrit is possible. Therefore, this study can provide the basis for a model which can monitor the real-time impact of PAHs released during oil spills. Instead of merely collecting dead birds, researchers can safely capture birds in mist nets, take blood samples and release birds. Micro-hematocrit tubes can be analyzed with portable equipment in the field. By doing so, exposure and possible recovery can be determined for the tested population or for individually marked birds.

Acknowledgments. We thank Predensa Moore, Falon Cartwright and the Bahamas National Trust for their support, assistance and co-operation with our sample collection at both The Reserve in Nassau, New Providence, and The Leon Levy Plant Preserve in Eleuthera, Bahamas and Rosabel Miro R., Directora Ejecutiva, Sociedad Audubon de Panama.

\section{References}

1. Leighton FA, Peakall DB, Butler RG. (1983) Heinz-body hemolytic anemia from the ingestion of crude oil: a primary toxic effect in marine birds. Science May 20;220(4599)871-3.

2. PHMSA Pipeline Safety, Data \& Reports http://www.phmsa.dot.gov/pipeline

3. Navy continues cleaning up 94,000 gallon jet fuel spill (https://www.usnews.com/news/beststates/virginia/articles/2017-05-12/cleanup-of-94k-gallons-of-jet-fuel-continues-at-navy-base).

4. Leighton FA. (1986) Clinical, gross, and histological findings in herring gulls and Atlantic puffins that ingested Prudoe Bay crude oil. Vet Pathol 23: 254-263.

5. http://www.gulfspillrestoration.noaa.gov/restoration-planning/gulf-plan/ Gulf Spill Restoration, Chapter 4. Injury to wildlife. 2015. p. 481.

6. Fair J, Whitaker S, Peterson B. (2007) Sources of variation in hematocrit in birds. Ibis 149:535-552.

7. Glomski,C.A., Pica, A., 2011. The Avian Erythrocyte Its Phylogenetic Odyssey, Science Publishers, Enfield, New Hampshire: pp. 113-125, 421-516.

8. Cray C. (2015) Reference intervals in avian and exotic hematology. Vet Clin Exot Anim, 105-116.

9. Booth CE, Elliott PF. (2002) Hematological responses to hematozoa in North American and neotropical songbirds. Comp Biochem Physiol A Mol Integr Physiol Nov;133(3):451-67.

10.Campbell TW, 1994. Cytology. In: Ritchie, B.W., Harrison, G.J., Harrison, L.R. (Eds) Avian Medicine: Principles and Applications. Winger, Lake Worth: pp. 199-221.

11.https://www.easycalculation.com/statistics/reference-range-lower-upper-limit.php (1975).

12.Runge CA, Watson JEM, Butchart SHM, Hanson JO, Possingham HP, et al. (2015) Protected areas and global conservation of migratory birds. Science Dec 4;350(6265): 1255-1258 doi: 10.1126/science.aac9180 


\section{Appendix: Tables}

Table 1. Hematocrit reference intervals for wintering neotropical migrants

\begin{tabular}{l|l|r|r|l|l}
\hline Species & & $\mathrm{N}$ & Mean & Range & RI (90\%CI) \\
\hline Ruddy turnstone & Arenaria interpres & 31 & 46 & $40-53$ & $39.9-51.8$ \\
\hline Prothonotary warbler & Protonotaria citrea & 20 & 46 & $39.5-52.5$ & $40-52.66$ \\
\hline Cape May warbler & Dendroica tigrina & 34 & 48 & $41-52$ & $40.91-53.23$ \\
\hline Black-throated blue warbler & Dendroica caerulescens & 30 & 47 & $38.5-60$ & $38.72-54.84$ \\
\hline Ovenbird & Seiurus aurocapillus & 36 & 43 & $36-49$ & $36.84-49.8$ \\
\hline American redstart & Setophaga ruticilla & 32 & 46 & $42-51.5$ & $38.83-53.63$ \\
\hline Palm warbler & Dendroica palmarum & 21 & 47 & $43-53.5$ & $40.91-53.23$ \\
\hline Gray catbird & Dunetella carolinensis & 30 & 44 & $38.5-51$ & $39.55-48.85$ \\
\hline
\end{tabular}

Table 2. RI partitions of warblers, family paridae. confidence intervals for sample sizes over 120 are reported as $95 \%$ CI while sample sizes from $20-40$ are reported as a $90 \% \mathrm{CI}$

\begin{tabular}{l|l|l|l|l|l|l}
\hline Family & time & $\underline{\mathrm{N}}$ & $\underline{\text { Mean }}$ & $\underline{\text { range }}$ & $\underline{\mathrm{RI}}(95 \% \mathrm{CI})$ & $\underline{\mathrm{RI}}$ (90\%CI) \\
\hline Paridae & Wintering & 234 & 46.13 & $35-60$ & $38.17-54.34$ & \\
\hline Paridae & January & 92 & 45.2 & $35-52$ & & $39.17-51.23$ \\
\hline Paridae & March/April & 136 & 46.52 & $35.5-60$ & & $39.11-51.28$ \\
\hline Paridae & Male Wintering & 94 & 46.9 & $42-60$ & & $40.54-53.6$ \\
\hline Paridae & Female Wintering & 55 & 45.95 & $35.5-52$ & & $39.72-52.18$ \\
\hline Paridae & Male January & 27 & 45.67 & $42-52.5$ & & $40.34-51.0$ \\
\hline Paridae & Male March/April & 67 & 47.4 & $42-60$ & & $40.71-54.08$ \\
\hline Paridae & Female January & 20 & 46.55 & $39.5-52$ & & $39.22-53.88$ \\
\hline Paridae & Female March/April & 35 & 45.6 & $35.5-51.5$ & & $39.74-51.46$ \\
\hline
\end{tabular}

Table 3. Hematocrit values for neotropical migrants not meeting criterion for reference intervals.

\begin{tabular}{l|l|l|l|l}
\hline Species & & $\mathrm{N}$ & mean & range \\
\hline Northern parula* & Parula americana & 16 & 44.84 & $35.5-50$ \\
\hline Worm-eating warbler* & Helmitheros vermivorum & 18 & 45.25 & $41-52$ \\
\hline Prairie warbler* & Dendroica discolor & 10 & 48.9 & $45.5-55.5$ \\
\hline Northern waterthrush & Seiurus noveboracensis & 5 & 43.5 & $41-46$ \\
\hline Black and white warbler & Mniotilta varia & 4 & 45.25 & $41-52$ \\
\hline Common Yellowthroat & Geothlypis trichas & 2 & 44.5 & $40-49$ \\
\hline Yellow-rumped warbler & Dendroica coronata & 1 & 45 & \\
\hline Painted bunting & Passerina ciris & 5 & 50.6 & $45.5-59$ \\
\hline Indigo bunting & Passerina cyanea & 3 & 49 & $44-57$ \\
\hline White-eyed vireo & Vireo griseus & 4 & 49 & $45-52.5$ \\
\hline Red-eyed vireo & Vireo olivaceus & 1 & 51.5 & \\
\hline Yellow-throated vireo & Vireo flavifrons & 1 & 52.5 & \\
\hline Yellow-bellied sapsucker & Sphyrapicus varius & 1 & 48 &
\end{tabular}

* indicates those for which histograms are shown in Figure 3 


\section{Appendix: Figure Legends}
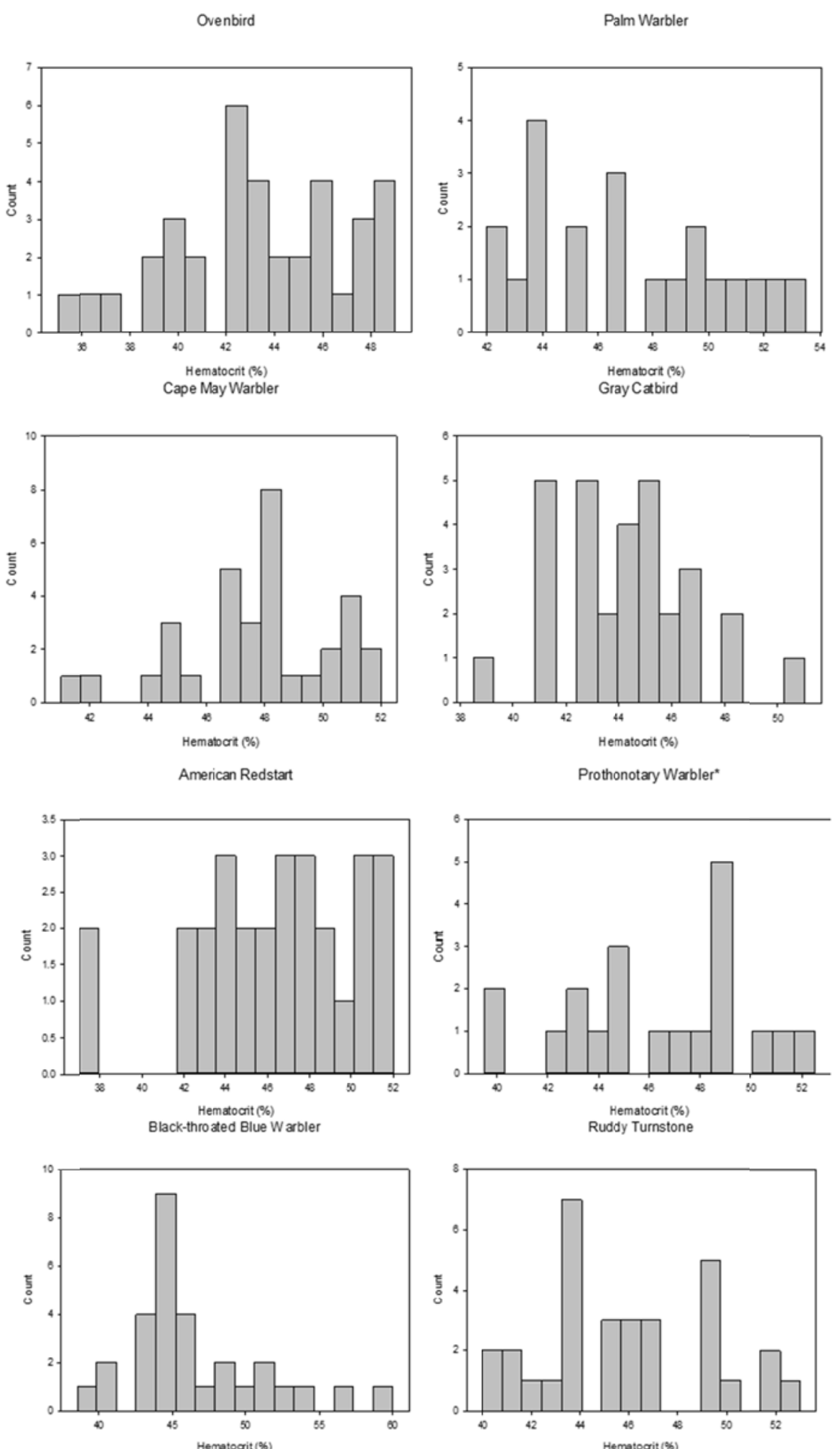

Figure 1. Wintering hematocrit values for neotropical migrant species. Histograms representing individuals are plotted at each HCT value according to new standards of the American Society of Veterinary Clinical Pathologists. Samples were taken in January and again in mid-March through mid-April prior to migration. *Values for prothonotary warblers are only from January. 

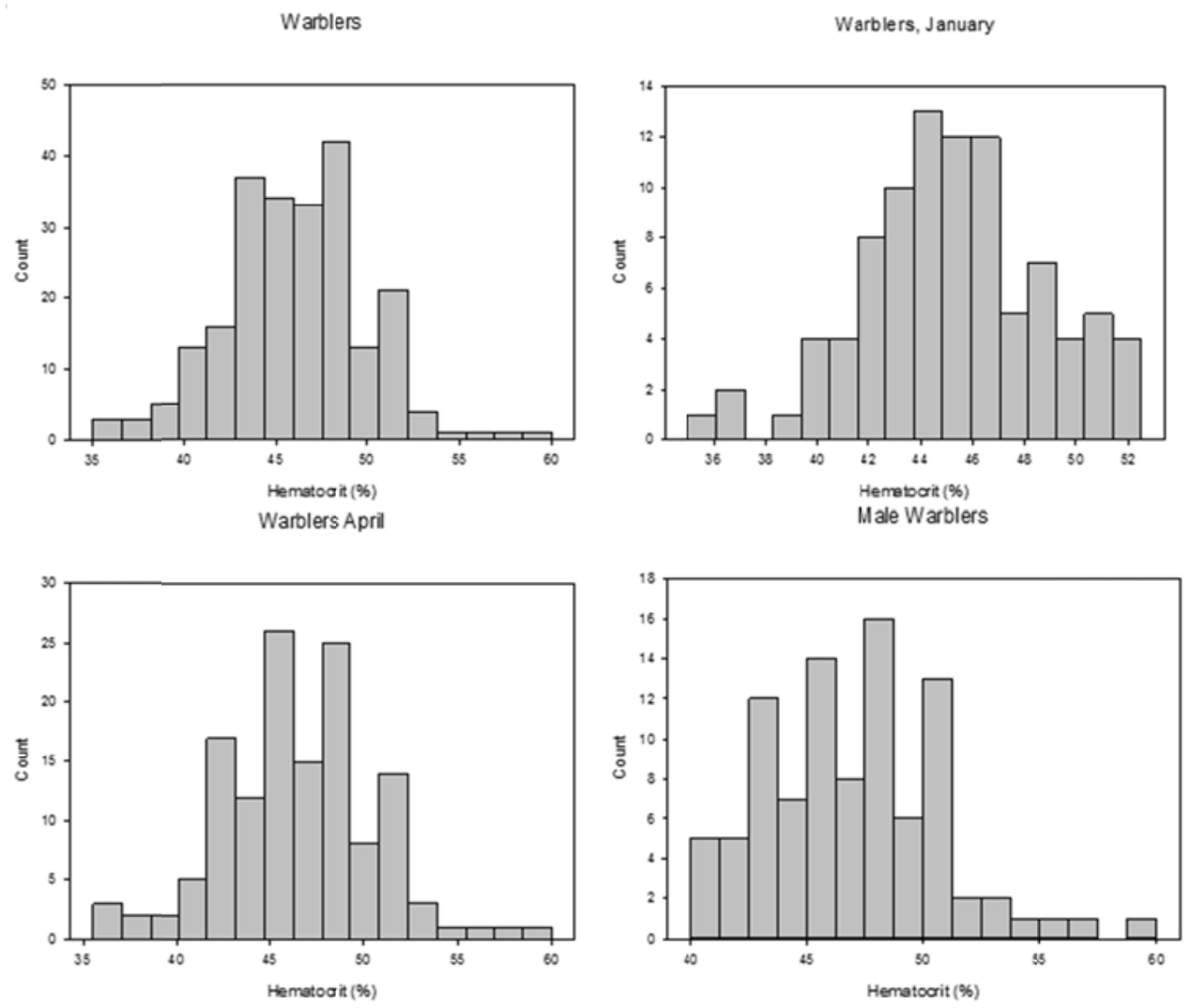

Male W arblers January

Male Warblers April
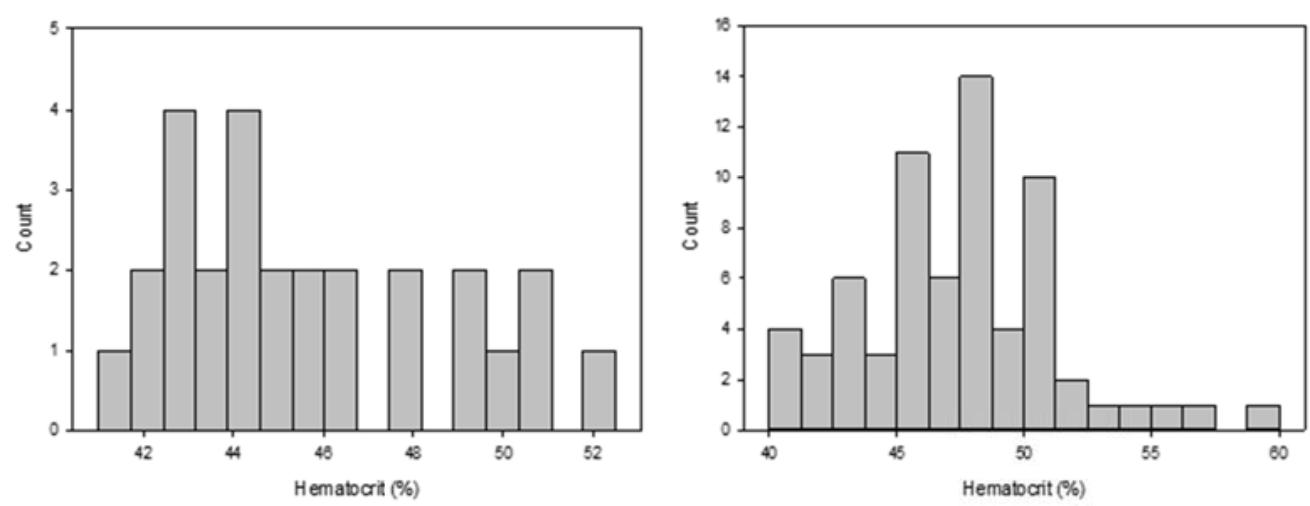

Female Warblers

Female Warblers January
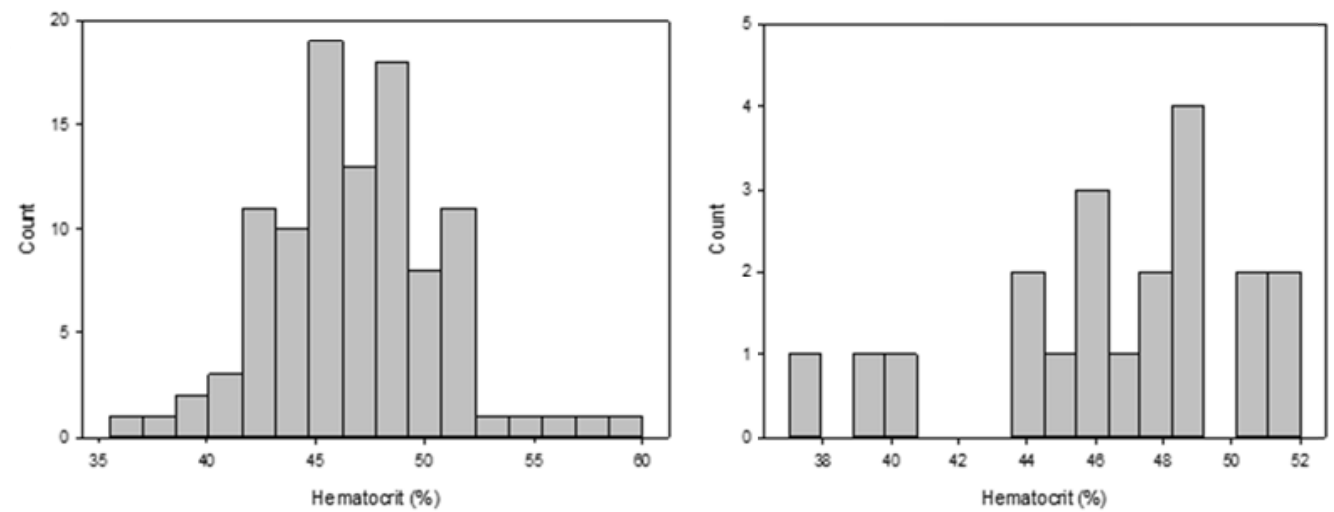
Female Warblers April

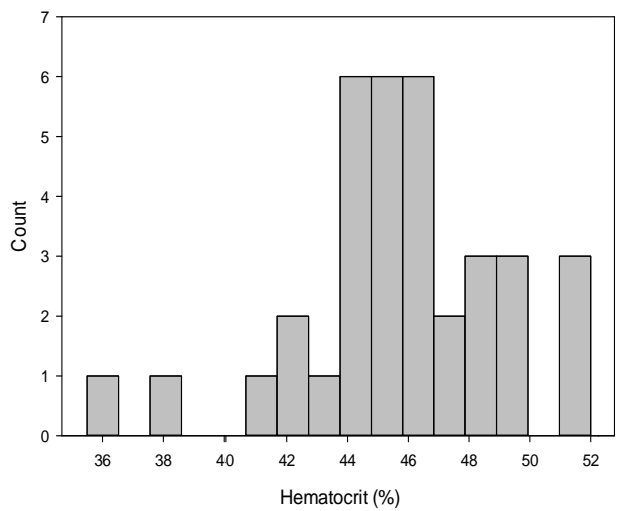

Figure 2. Wintering hematocrit values for the warbler family, Paridae, and partition values for January, April, Males and Females. Seven species of warblers plus the six included in Figure 1 are included in this data.

W orm-eating W arbler
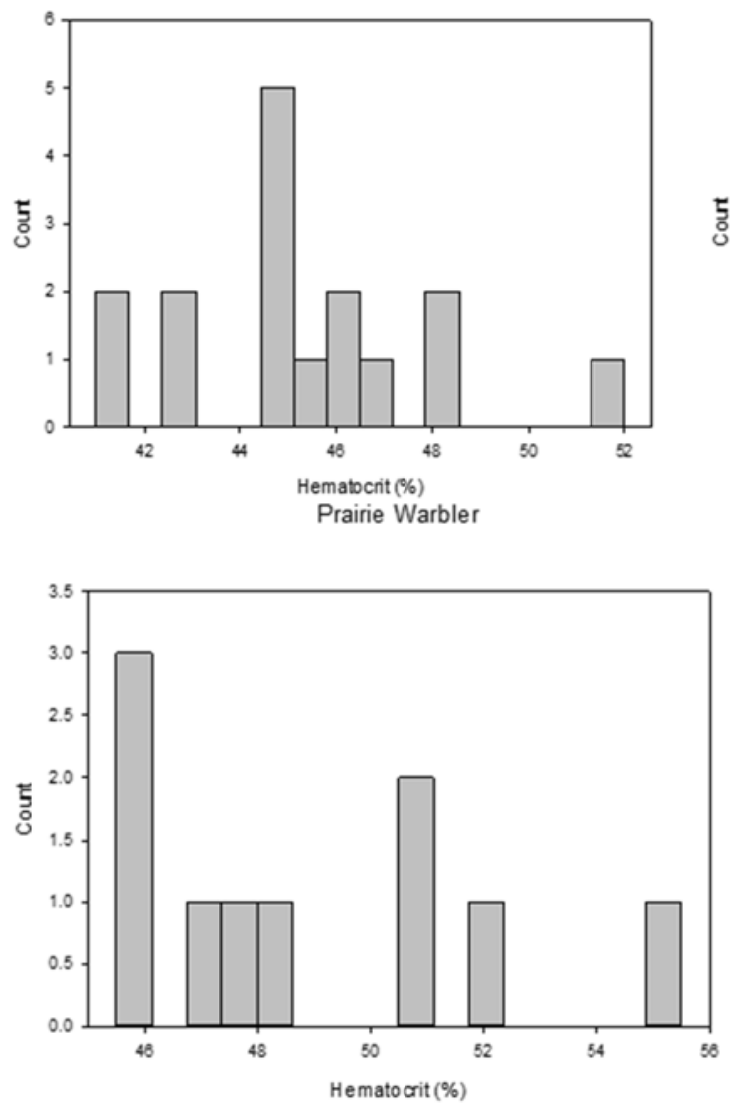

Northern Parula

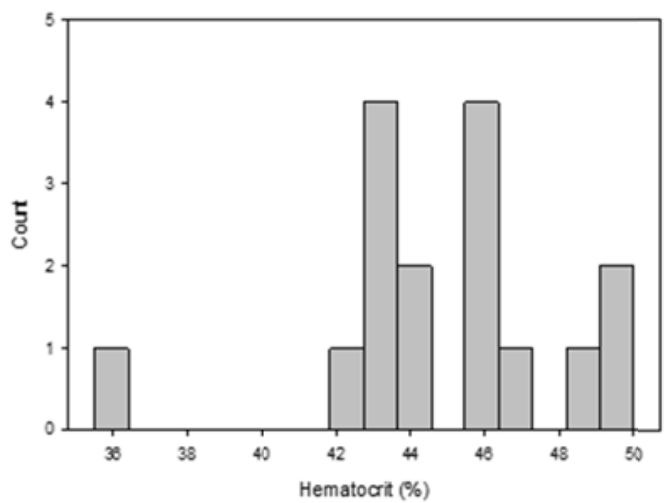

Figure 3. Wintering hematocrit values for those neotropical migrant species not meeting sample number requirements. Histograms for three species of warblers with sample sizes of 10-20 are shown according to new standards of the American Society of Veterinary Clinical Pathologists. 